\title{
Lighting the fuse: Cultivating the masculine physics habitus - a case study of Victor aged 10-18
}

Louise Archer, Julie Moote and Emily MacLeod

UCL Institute of Education

\begin{abstract}
This chapter presents a longitudinal case study analysis of Victor, a young man who was interviewed from the ages of 10 to 19 , together with his mother, Sam, and who went on to study for a degree in astrophysics. We apply a Bourdieusian conceptual lens to the data, to explore how interactions of capital, habitus and field combine to possibilise Victor and his trajectory to being/ becoming a physicist. We also identify specific alignments of his habitus and capital with dominant notions of masculinity and 'cleverness' that are demanded and normalised within physics and which, we argue, are key to the reproduction of the elite nature of physics.
\end{abstract}

\section{Introduction}

"I mean sort of what got me into Astrophysics is by pure sort of - I wouldn't say by chance or mistake, because I was already along those lines [...] the fuse was already there. What lit it was by mistake" (Victor, Year 13 interview, age 17/18)

This chapter attempts to understand how and why it is that (white) middle-class boys, like Victor, are more likely than many other students to end up studying for a physics degree. In particular, we use a Bourdieusian lens to explore how physics identity is shaped by interactions of habitus, capital and field, such that not only are some students more likely than others to see physics as potentially 'for me', but distinctive dispositions are also cultivated and demanded by the field of physics. In short, we examine how physics students 'become themselves' (Webb, Schirato, \& Danaher, 2002, p. xii), arguing that, the 'fuse', which Victor refers to (above) as being a precursor to his physics interest, can be understood as constituted through particular configurations of habitus and capital, such that what he calls 
the 'mistake' that ignites his physics trajectory, when viewed through this lens, is neither random, singular nor unexpected.

\section{A Bourdieusian lens}

Bourdieu's sociological theory provides a compelling framework and a set of valuable analytic tools for understanding the reproduction of social inequalities within society. At the heart of Bourdieu's theory is the idea that interactions of habitus, capital and field produce patterns of privilege and inequality within society.

Habitus refers to the internal framework of socialised, embodied dispositions that a person develops over time. Habitus provides us with 'feel for the game', and a sense of what is normal and desirable for 'people like me' (Bourdieu \& Wacquant, 1992). It embodies both individual and collective histories - that is, the habitus is not purely individualistic but is profoundly social and collective (or as Bourdieu terms it, "the subject is not the instantaneous ego of a sort of singular cogito, but the individual trace of an entire collective history", Bourdieu, 1990: 91). The habitus is both shaped by experience and, in turn, shapes our views and interactions with the world. In Bourdieu's words, it can be understood as a 'system of structured, structuring dispositions' $(1990$, p. 52), meaning that it is both a product of socialisation (i.e. it is structured) and provides a guiding framework for how we experience, interpret and interact with the social world (i.e. it is structuring).

Capital refers to cultural, social, economic and symbolic resources (or 'accumulated labour', as Bourdieu terms it, 1986, p. 241) that a person may possess and accrue. In this respect, capital is the 'hand' you can play in the game. Capital exists in relationship with habitus and field. For instance, the value of capital is determined by the field within which is operates ('Capital does not exist and function except in relation to a field', Bourdieu \& Wacquant, 1992, p. 101). Within any given field, the most powerful forms of capital will be those whose value can be most readily converted into symbolic forms that match the requirements of the field. Hence the field determines value of capital but the accumulation of capital also, in turn, shapes the field.

Field refers to socially and historically constructed socio-spatial arenas that are constituted through differential power relations. Field thus represents a 'space of positions 
and position-taking' (Bourdieu, 1993, p. 30), which Bourdieu imagines as a 'force field' that constitutes the 'rules' of the game:

A field is a structured social space, a field of forces, a force field. It contains people who dominate and others who are dominated (Bourdieu, 2010, p. 37)

The relationship between habitus, capital and field will shape a person's experience within that field. For instance, where there is a strong alignment, students experience education as a 'fish in water' (Bourdieu \& Wacquant, 1992, p. 127). Each field (and sub-field) has its own logic of practice. Hence, as we have argued elsewhere (Archer et al., 2017; Archer et al., under review), we suggest that school physics can be understood as a field, with its own logic of practice, containing differently positioned social actors (e.g. teachers, students) who deploy and compete for a range of (cultural, social and symbolic) resources.

While Bourdieu's theory has been extensively and successfully applied to understanding the reproduction of social class inequalities (notably through education), opinion has been more divided regarding its application to gender, given that 'Bourdieu's social theory had relatively little to say about women or gender' (Adkins 2004, p.3s). However, many feminists have found Bourdieu's conceptual tools both useful and resonant with a feminist approach, particularly: his constructivist structuralism (Fowler 2000) and undercutting of the essentialist/non-essentialist divide (Moi 1990); his foregrounding of embodiment (as core to the habitus); the notion of power and social position taking as constitutive of field; the concept of symbolic power/ violence; and his non-Cartesian 'notion of the subject as not simply engaged with the world, but in the world' (Adkins 2004, p.10).

Towards the end of his career, Bourdieu did attempt to explicitly engage with gender, as exemplified by his book Masculine Domination (La Domination Masculine), based on an anthropological study of the Kabyle society. However, attention has been drawn to some key limitations of his framework for feminist theory. For instance, because his conceptualisation of gender was based on his study of a comparatively less complex and undifferentiated tribal society, his work has been critiqued for not extending to contemporary, highly complex societies in which there are diverse understandings and performances of masculinity and femininity (that is, it assumes an 'understanding of gender relations in contemporary, differentiated, heterodox societies on an outdated anthropological study of an undifferentiated society', Adkins 2004, p.16). But also more generally, it is widely recognised that as a consequence of his focus on social reproduction, Bourdieusian theory has difficulty 
explaining social change. Further critiques have also been levelled at his assumption that the habitus is driven by capital accumulation. For instance, Reay's 2004 analysis of mothers highlights how emotional capital can be expended for the benefit of investing in others, to the detriment of the self. Yet, such reservations notwithstanding, his work remains a productive resource for feminist theory and research, particularly, as exemplified by the contributors to a 2004 special issue on Feminism and Bourdieu, which showcased how feminists are reworking, redefining, extending and transforming his work in order to better understand contemporary gender inequalities in western societies (see Adkins 2004). For instance, as McLeod argues, Bourdieu's concept of field is rich and can be usefully extended and applied to theorise how dominant notions of gender (both how it is expressed and experienced) change and evolve across time and context. That is:

how gender identities and relations are changing or being re-articulated in new but familiar ways. In such a view, a more uneven and less seamless relation between habitus and field is possible, and this offers scope for feminist analysis of change and continuity (2005, p.12)

Moreover, although Bourdieu is grounded in structuralism, as McLeod discusses, his 'denaturalizing' of gender and his view of gender as a socio-historical and arbitrary 'social construction' (2001, p. 3) fits with feminist post-structural theorizations of gender. As McLeod further explains, Bourdieu's foregrounding of the embodied nature of habitus (hexis) aligns well with much feminist gender theory and concerns with embodiment. However, as McNay (1999) argues, Bourdieusian theory falls down in its assumption of unitary, rather than multiple, gender subjectivity:

[Bourdieu] significantly underestimates the ambiguities and dissonances that exist in the way that men and women occupy masculine and feminine subject positions ... masculine and feminine identities are not unified configurations but a series of uneasily sutured, potentially conflictual subject positions. (McNay, 1999, pp. 107108)

Hence in this chapter, we attempt a feminist application of Bourdieusian theory, exploring what this lens can offer to our understandings of the intractable, gendered (masculine) nature of post-compulsory physics participation - focusing particularly on how some students (notably middle-class boys, especially from white or South Asian communities) are more 
likely to be socialised into seeing physics as potentially 'for me', including the cultivation of particular (masculine) dispositions and the requirement of particular capital.

\section{Methods/ data set}

Data drawn on in this chapter were collected as part of the Aspires/ Aspires2 project, a ten year, mixed methods study of children's science and career aspirations from age 10-19 funded by the UK Economic and Social Research Council. The dataset comprises large-scale national surveys of a cohort of students as they progress through primary and secondary schooling, combined with in-depth longitudinal interviews with a subset of young people and their parents.

The survey data referred to in this chapter relates to the wave conducted with students at age 17/18 in England. The questionnaire was revised, validated and piloted with 200 students before being administered to a national sample of c.8,000 17/18-year-old students (Year 13). Following data cleansing (which involved removal of duplicate or incomplete responses, as well as any participants with missing ethnicity and gender data), 7,326 students remained in the sample for analysis. Students from 265 schools completed the survey (237 statemaintained schools; 28 independent schools), which was roughly proportional to the overall national distribution of schools in England by region, school type, attainment and free school meals provision (as a measure of socioeconomic status).

Longitudinal interviews were conducted with 61 young people (26 male, 34 female, 1 other) and 65 of their parents (50 female, 15 male). All these participants had been previously tracked since students were aged 10/11 (Year 6/ Y6), with repeat interviews at age 12/13 (Year 8), 13/14 (Year 9), 15/16 (Year 11) and age 17/18 (Year 13). Interviewees came from a broad range of socioeconomic classes and ethnic backgrounds (43 White British [25 female, 17 male, 1 other], 3 Black [2 female, 1 male], 5 White European [3 female, 2 male], 6 Asian [2 female, 4 male], 4 Mixed [ 3 female, 1 male]). Interviewees had been recruited to take part in a study of their science and career attitudes and aspirations. Interview topics covered a broad range of areas, including general (non-science specific) areas such as general interests, pastimes, constructions of gender identity, peer relations, their family, aspirations and future educational and occupational plans. Science and STEM-specific areas of questioning included views on science, technology, engineering and maths, views on school science and 
reasons for post-compulsory science (non)participation. Interviews were conducted by members of the research team, who identified as White, middle-class women from British $(n=2)$ or North American backgrounds $(n=2)$. Participants were invited to choose a pseudonym to maintain anonymity in any reporting. Therefore the pseudonyms cited in this paper reflect the personal choices of the interviewees. In this chapter we focus particularly on the case of Victor, the only boy in our interview sample to have entered onto a physics degree course when students were followed up in the Autumn after they had completed school at age $18^{\mathrm{i} .}$

Quantitative analyses of the survey data were conducted by the second author using SPSS (including series of one-way ANOVAs with post-hoc tests to explore group differences across a range of background factors and for categorical variables, descriptive crosstabulation (chi-squared) analyses to identify basic relationships, with additional adjusted residual analyses performed, see Moote and Archer (2017) for further justification of this procedure). Qualitative data were initially coded by the research team using the NVivo software package. In the first sweep, coding was used to identify top level themes such as 'aspirations', 'views of science', 'home and family', and so on. The lead author then subjected the data to a more theoretically-driven analysis in line with the project's conceptual framework, to identify instances of habitus, capital, field, hexis, pedagogic work and masculinity. Relationships between these concepts were then explored and developed through an iterative moving back and forth between coded data and theory/ literature to produce a further set of analyses, in which notions of 'cleverness' and physics masculinity were identified and re-applied to the data (to identify further instances).

\section{The distinctive physics habitus}

Across the project as a whole, data collected from the surveys and interviews painted a common picture, in which the vast majority of students (irrespective of their post-16 routes) viewed physics as being not only 'hard' but also the 'most difficult' science (see also Archer et al., 2017; Archer, Moote, \& MacLeod, under review). Statistical analysis of the survey data suggested that students who took Physics A level (an Advanced Level highly academic postcompulsory course, typically studied at age 16-18) expressed a distinctive set of views compared to both other science students (that is, those taking biology and/or chemistry, but not physics) and compared to the wider set of all students. For instance, as discussed in 
Archer et al., (under review), physics A level students were significantly more likely than other students to feel confident in their mathematical abilities and tended to express the most positive views of science. They were also significantly more likely to express stereotypical views of scientists as being 'odd', 'geeky', 'male' (with chi-squared tests showing large effect sizes ${ }^{\mathrm{ii}}$ ).

We interpret these patterns as potentially marking out the contours of a 'physics habitus' that is, a configuration of socialised dispositions that are structured and cultivated by the field of (school) physics and which, in turn, structure young people's views and experiences of the subject and shape the extent to which they feel it is 'for me', or not.

We now seek to add richness and depth to the bones of this statistical picture using a case study of Victor, to try to better understand how these distinctive patterns emerge.

\section{Introducing Victor}

Victor is a white British middle-class boy who lives in the South East of England. Since we first met him at primary school, Victor had aspired to a science or STEM-related career. For instance, at the age of ten he told us "I'd like to be a scientist, an inventor, and an engineer" and, when asked how long he thought he would continue studying science, he asserted "a long time [...] I'm going to do that in university". Between the ages of 12 and 14 he wanted to be a science teacher and by the age of 15 he had decided to become an astrophysicist - an aspiration that he continued to hold into university.

Victor lived with his mother (a physiotherapist), father (an engineer and master craftsman) and younger brother. He attended his local state primary and secondary school until at age 18, having completed A levels in physics, mathematics and economics, he began an astrophysics degree at a post-1992 university in the South East of England.

\section{Victor's 'physics habitus' and dispositions}

Victor's physics habitus was consistent with the patterns observed in the survey data, in that he was confident in his mathematical abilities, expressed positive views of science and tended to see science as male-dominated. Analysis of his interview data also allowed for further fleshing out of his physics habitus, which as discussed next, included: a high level of STEM 
literacy and frequent 'talking science'; a particular interest and fascination with physics; and intellectual curiosity in the way the world works. As discussed next, all of these aspects were evident not only in his academic engagement but also suffused Victor's leisure time.

Across his interviews, Victor exhibited considerable STEM literacy from an early age and regularly 'talked science' (Lemke, 1990) in the interviews. From the age of ten onwards, he conveyed a knowledge of scientists (e.g. Stephen Hawking, Einstein), inventors and engineers (e.g. Benz) and displayed a mastery of scientific terminology. Indeed, all his interview transcripts were peppered with examples of his use of scientific terminology and concepts. For instance, when Victor was ten, his mother, Sam, reflected on his everyday use of scientific concepts and language, which she termed 'the right kind of words':

"I think the other day someone said to him 'What do you use a mirror for?' and he said 'It reflects light' - after someone else had answered. And I thought 'Oh right, you're just using the right kind of words' (Sam, Year 6 interview).

Victor's physics habitus was characterised by a general interest in science and a particularly keen passion for physics. As he reflected in his Year 9 interview, "I'm always thinking about Science in my head and I think that's a good thing". He also recognised in this interview that his interest in science was continuously increasing (or 'excelling' in his words). For instance, when asked how he thought his interest in science had changed since he was younger, Victor replied:

"I think it's sort of excelled a bit and I've more of ... I think more of my time is spent thinking about Science than thinking about other things. Every now and then when I start thinking about something, it somehow always leads towards the plan that I have for doing something with hydroelectricity but ... yeah. [...]... I'm always drawing or sketching something along the lines of Science" (Year 9)

It was in his Year 11 interview that Victor's interest in physics came to the fore: 'I've seen what sort of all of the areas are in-depth and Physics is the one that fascinates me the most". Victor did not see physics as just a school subject, rather it was a source of personal interest and identity, both in and out of school. For instance, when asked about his out of school interests, Victor replied: 
"At the moment I'm into playing squash with my dad on Saturdays. Um, I also quite like computer gaming as well, but apart from that my main interest is Astrophysics. I just kind of like space quite a lot" (Year 11).

This interest continued to increase through A level into a real passion for physics: "Physics is great, I love Physics. Er, I love the concept of Physics" (Victor, Year 13).

Victor's science/ physics habitus was also underpinned by an intellectual curiosity and interest in how the world works. As he recounted in his first interview, age 10:

"Well I just think it's fascinating the way things work. I've got this book on the way things work and it was very big, and then they just had things that were invented like in the olden days, but we still use today" (Year 6).

Indeed, from when we first met him, Victor had defined himself through his science activities and interests:

Interviewer: So we'll start off quite basic - can you tell me a little bit about yourself?

Victor: Um, well I like doing things to do with science. I like making things, making things move, and then I like making things go up in the air. [I: Okay] I tried that with baking soda and vinegar - I tried it with my brother and it was so much fun. Um, I also like animals and wildlife. (Year 6 interview)

By the age of ten, he had created a book, or journal, in which he listed all his ideas and plans for inventions:

“I've put it down all in a book called 'Impossible Things'.. I've got a time vortex, a cloning thing, robots that do like everything, and loads of other things" (Year 6).

Across the interviews he also described setting himself personal research projects, which reflected his long-held ambition to become a scientist, as the following extract from his Year 6 and Year 9 interviews exemplify:

Victor I want to be a scientist because ... well science is like ... when you think about it, science is just amazing. I've given a question to myself, and I'm trying to do a little bit of research on it - it's what creates wind.

Int Mm. And what have you done so far?

Victor Well so far I'm not too far through, and all I know is that wind is like a pushing force. 
Int And how do you plan to find out more about what creates wind?

Victor I can use the internet and then I can like use my ... computer and friends that want to be scientists. (Year 6 interview)

Victor: I'm interested in creating things at the moment, inventions, I'm thinking of doing something, I don't know if it will work out, but um ... yeah [...] I've been thinking of ... along the lines of hydroelectricity, I'm thinking of the generalities and everything and I'm not entirely sure, but it's along those lines. (Year 9 interview).

To understand what produced this distinctive habitus, we now apply a Bourdieusian lens, exploring how interactions of capital, habitus and field, along with specific alignments of his habitus and capital with particular notions of masculinity and 'cleverness' that are demanded and normalised within physics, combine to possibilise Victor and his trajectory to being/ becoming a physics student.

\section{Victor's science-related family habitus and capital}

As has been widely noted in the literature, the middle-classes tend to be highly successful at combining economic, cultural, and social capital to produce academic achievement (e.g. Dika $\&$ Singh, 2002). Through the process of socialisation and the translation of capital, these families are able to cultivate particular values, attitudes, expectations, and behaviors in their children that enable them to succeed educationally (e.g. Israel, Beaulieu, \& Hartless, 2001; Martin, 2009; Perna \& Titus, 2005; Sandefur, Meier, \& Campbell, 2006), including through private schooling, private tuition, and extensive enrichment activities (e.g. Vincent \& Ball, 2007). However, as we have noted previously, in the case of promoting successful engagement and trajectories in science, it is a family's possession and deployment of specific science-related forms of cultural and social capital (and the deployment of economic capital to support the accrual of science capital, Archer et al., 2015 - I.e. science-related forms of cultural and social capital, as embodied in the habitus) that is particularly influential (DeWitt et al., 2016). Indeed, our research has found that young people with high levels of science capital are significantly more likely to aspire to continue with science post-16 and to espouse a ‘science identity' (e.g. Archer et al., 2015.) 
Victor grew up in a home rich in STEM-related capital. His parents were STEM enthusiasts (as his mother, Sam, explained in the first interview, "I'm hugely, hugely interested in science”) and had STEM-related jobs, in physiotherapy and engineering respectively. Victor's grandfathers on both sides were also engineers, which his mother interpreted as an essentialised, or almost inherited, family connection, using the terminology of it being 'genetic': "Well my husband's an engineer, his father was and my dad was, so I think it's, you know, quite genetic with [Victor]").

Victor enjoyed considerable STEM-related social capital, not just through his family members but also through their wider social networks. For instance, from the age of 10 , Victor told us about the number engineers he knows, naming several of his father's friends. He also benefitted from social capital in the form of like-minded peers. For instance, his early primary friendships enabled him to enjoy talking about science with peers and to have a rich, playful and socially rewarding engagement with science which also provided Victor with new science capital and knowledge. For instance, as exemplified in the following extract, Victor's friend, Finch, liked science and had introduced him to nuclear physics and the periodic table. The boys also used to enjoy science-themed imaginative play together:

"Well I think my friends are [into science], cos I think it was nuclear physics that [Finch] liked and ... well I talk to him a lot and then he just goes off talking about hydrogen, oxygen, the other one that he ... he did the whole of this sort of table thing - I can't remember its name but ... I think it was the periodio- ... no ... can't remember. // Well [Finch] has the same desire to make things that go zap. We're trying ... in our imagination games there's something called the zappy and it can teleport you, and you can also use it as a laser. [Int: Okay.] We tried making it at his house when I went round there, and then I tried to make one of his machines work, but then it did an overdrive and one of the batteries leaked". (Victor, Year 6).

Victor continued to have 'science-y' friends through secondary school - which again provided further spaces and opportunities to develop a science habitus. As the following quote exemplifies, these relationships also provided cultural capital and, as Victor suggests, made him first aware of the field of astrophysics:

"I think a friend just mentioned the word Astrophysics and I was thinking I like Physics and I like Astronomy, because I was really keen on Astronomy sort of thinking I really like sort of the space itself and things like that and everything in the 
universe, but then I didn't really want to just study the stars. I thought that's been done quite a lot in history. I want to do something along the lines of how everything works and then my friend said Astrophysics and sort of by chance that's exactly what I want to do" (Victor, Year 11).

As we have previously found to be common among 'science families' (those with high levels of science capital, Archer et al., 201), Victor's childhood was also characterised by frequent informal engagement with science, through regular consumption of science-related television and media and through his many home science resources, such as science kits (“yeah I've got one of those kits where you just mix things together and make different things. Once I made a big explosion", Year 6). For instance, at age ten Victor told us about how he liked making moveable vehicles and was planning on building a helicopter. He also enjoyed reading science books, with a notable one being astrophysics-related ("it was called 'My First Guide to the Universe' and I learnt about how things were affected by gravity"). His mother concurred, and described the motorised cars and rockets that he had built and how he liked making explosions, using science kits and "he was trying to make an electrical circuit recently, you know make a bulb light up" (Sam, Year 6).

As our previous research has shown, families with higher levels of science-related resources (capital), tend to actively promote, develop and sustain their children's science interest and aspirations, through the foregrounding of science within everyday family life, for instance, by providing science kits, watching science TV together, discussing science in everyday conversations, going to science museums, and so on (Archer et al., 2012). In this respect, Victor's family can be read as a typical example of such a 'science family'.

Victor also recounted trips to the science museum, which had made an enduring and visceral impression on him, explaining how he 'can still feel' the effects of a particular exhibit when he remembers it:

It was a long time ago. I can remember playing a game and then there was this long pillar in the middle and it was like full of static, and then I touched it and then the static just came down the line and you're like 'Ahh' and it tickled me. Yeah I can still feel it in myself. (Year 6)

He also described being inspired by the famous physicists that he learned about through his consumption of science media. For instance, at age 13/14 he explained: 
"Well Science, I got into because, you know, people like Stephen Hawkins and other people like Einstein, Newton, I thought there was something there because like the science of the world is really complicated [...] So I thought like I could contribute to doing that or ... um it really came about when I was doing Science because I was fascinated by the fact that if you had this and you mixed it with this, it becomes something else which can do this. I found that really interesting that ... just what ... what it ... what nature can do by itself I thought was really interesting" (Victor, Year 9).

Over the years, Victor continued to do a substantial amount of STEM-related activities in his leisure time, although these shifted more towards science-related computer games. For instance, at age 15/16 he described his love of a space-related game, which he claimed has sparked an interest in astrophysics:

“There's one called Kerbal Space Program. It's a simulator of space and that's what's kind of got me into the whole Astrophysics sort of thing [...] you get sort of command modules and things and fuel tanks and engines and different types of things and you have to sort of teach yourself how to stage things properly, how to enter an orbit, (inaudible 00:16:34), things like that and it's got a whole solar system, so you can go and visit loads of planets. It's all real, sort of real time in game, so all the planets move round $[\ldots]$ it's accurate sort of in proportion to the solar system, but it's got like I think the atmosphere's thinner, so you can get out into orbit a lot easier" (Year 11 interview).

His out-of-school interest and engagement was further supported and reinforced through his social capital, for instance, in his Year 11 interview, Victor described going out stargazing with a friend of his father.

Victor's home capital was operationalised and realised through his parents' practice of concerted cultivation (Lareau, 2003), which both Victor and Sam recognise as being consistently enacted over time. For instance, in the Year 6 interview, Sam described her 'hands on' parenting style:

"Yeah I feel I am quite involved as a parent, I do his reading with him and his homework. Yeah ... no I feel very involved actually" (Sam, Year 6) 
Similarly, she described how her close involvement was still evident when Victor was aged 18 , exemplified by the considerable effort that she put in to researching and helping Victor to explore post-18 routes, such as higher apprenticeships and degree courses. Sam was highly industrious (and the main driver in) seeking information, requesting help from the school and extensively researching different options:

"Perhaps I'm just being a helicopter parent and wanting too much, I don't know. But I just feel that the work that has been done to find everything out has just been me [laughs]" (Sam, Year 13).

As Sam explained, "that's how we look at things, so you know if that door closes, it means that we've got to keep looking, pushing other doors". Bourdieu (1986) describes capital as accumulated labour and argues that the embodiment of capital and its incorporation into the habitus, such as through tastes, dispositions, and so on, is gradual and takes time. We interpret Sam's industriousness as exemplifying the considerable labour that is required to convert capital into the habitus and to realise it as social advantage - it is not an automatic or passive process. In other words, producing one's child as a viable, successful scientist requires considerable time, resource, strategy and 'work' to ensure the 'correct' translation of capital into social advantage. Bourdieu argues that the conversion and transformation of capital requires labour, particularly time and effort by mothers, to generate cultural capital. While we may take some issue with Bourdieu's somewhat gender stereotypical assumption that mothers are necessarily the prime socialising agent, we find that his description of this process (as "diffuse, continuous transmission within the family [that] escapes observation and control") fits well with our data in the case of Victor, as indeed does Bourdieu's conclusion that the purpose of this process is so that "the educational system seems to award its honors solely to natural qualities". (Bourdieu1986, pp. 25-26).

\section{School}

Beyond his home capital, Victor also described deriving resources and support from particular school teachers, who provided another 'spark' for his interest and aspiration:

"Our old Physics teacher [name] was really good at teaching. He was also quite interested in space and that sort of, I could talk to him about things that were going on and that sort of sparked my interest" (Year 11) 
His mother, Sam, also recognised the value of this teacher for supporting Victor's trajectory:

"They had a new Physics teacher towards the end of last year who is an astrophysicist [...] Thank God for that" (Year 13)

However, Sam also described how this capital was variable, in that not all of Victor's physics teachers had been supportive or effective. Indeed, she felt that he had "done well for a state school student", given that many state schools in England (like Victor's) experience particularly acute issues with the recruitment and retention of physics teachers (e.g. Osborne \& Dillon, 2008). Sam described his science teachers as having been "either superb or appalling”, explaining: "He's had some superb teachers, he's got some at the moment ... he's had some absolute stinkers ... but that is because schools can't get science teachers".

The family negotiated the challenges and risks posed by the perceived variable quality of school science teaching by mobilising their economic and social capital to provide Victor with private tutoring, to support his attainment. As Bourdieu argues, the habitus can be strategic and spontaneous, enabling his family to be responsive to new situations (such as issues with teaching and threats to his attainment), albeit within the limits of what is 'thinkable' (as unconsciously driven and guided by the socialised habitus).

'the habitus, like every 'art of inventing', is what makes it possible to produce an infinite number of practices that are relatively unpredictable (like the corresponding situations) but also limited in their diversity. In short, being the product of a particular class of objective regularities, the habitus tends to generate all the 'reasonable', 'common sense' behaviours (and only these) which are possible within the limits of these regularities.." (Bourdieu, 1990, p. 55)

In other words, his family's strategic deployment of capital can be understood as both a conscious and unconscious function of the habitus, guided by the imperative of the social reproduction of privilege (i.e. to try to ensure class advantage through the production of educational 'success').

\section{The 'naturalisation' and embodiment of Victor's science/ physics identity/ habitus}

Beyond the mobilisation of capital, we also wanted to explore some of the mechanisms through which a specific science/ astrophysics identity was cultivated and embodied within 
Victor's habitus. Our reading of the data identified a cluster of narratives that seemed to be influential and important to this process and which 'possibilise' (Butler 1990) and mark Victor as a legitimate science subject. For this aspect of the analysis, we combine our Bourdieusian lens with a feminist poststructuralist lens.

Our feminist reading of Bourdieu recognises a performative aspect of habitus, in which identity performances are produced through and with the 'embodied history' of the habitus (which is turn is produced through a dialectical relation with the field). That is, we posit that the identity discourses which a person has to draw on will be shaped by their history, body, capital and interactions with the field. As discussed above, we conceptualise the habitus as strategic, performative and productive - albeit within the limits of its conditions of production. In this respect, we consider the identity narratives produced by Victor, his family and wider others (e.g. school teachers and peers) as being both structured by, structuring and productive of, the habitus.

Over the years, Victor articulated a set of coherent identity narratives and performances in which he produced himself as a 'science person'. For instance, he often described himself as 'always thinking about science'. He also presented himself as a dedicated science student ("Well, science I put in 99\% [effort] like all the time. Other subjects I'm like 80, 90\%") and felt he was achieving well and had a 'natural' aptitude for the subject ('always getting the stuff that we need to do down straight away");

Interviewer: And how do you think you're doing in science at the moment?

Victor: $\quad$ I think I'm doing very well.

Interviewer Mm. And why do you think that?

Victor: Well it's because every time we do Science I'm like always getting the stuff that we need to do down straight away.

Importantly, Victor's self-identification as a 'science person' was also recognised and legitimated by others. In particular, across all the interviews, his mother, Sam, articulated a strong and consistent discourse that naturalised and essentialied Victor's science identity as something that is in his 'genetics', 'bones' and 'brain'. For instance, as quoted earlier in the chapter, Sam described how having various engineers in the family (two grandfathers and his own father) rendered engineering 'quite genetic' ('natural') for Victor. She also made 
references to engineering being 'in his bones', 'brain' (e.g. "[Victor] has got kind of an engineering brain", Year 6) and as being a 'natural' aptitude that he was 'born with':

Yeah Science ... well in Year 3 he got like 97\% in his Science or something - that's something that seems again to come easier to him I think - he's quite fascinated. [...] He was doing something on magnets the other day and he kind of just understood about forces of repulsion ... yeah so that really delights me actually when I see him doing that kind of thing, because I think 'Oh right, that seems to be where your natural ability lies' (Sam, Year 6).

[Victor] always wanted something on the moon or satellites or how things work - all this kind thing, he's always just had that kind of brain, taking things apart [...] Sometimes you're just born with those kind of ... yeah. And I think ... yeah I just think that's something that he was just sort of born with, just being very interested in how things work (Sam, Year 13).

In their later interviews, Victor and his mother both recalled examples from earlier in his life which they explained as demonstrating a 'natural' and enduring interest in space. This became a familiar and well-rehearsed family identity narrative over the years:

"[I remember] when we went to the library to get sort of space books and my mum told me the other day 'you always used to go and get like a book on Astronomy and then tell me stuff about it' (Victor, Year 11).

Bourdieu suggests that the habitus is 'embodied history, internalised as a second nature and so forgotten as history' and is thus 'the active presence of the whole past of which it is the product' (Bourdieu, 1990, p.56). We suggest that Victor and Sam's talk can thus be read as active performances which both remember and constitute (as identity practices in their own right) this embodied history. That is, we suggest that such family narratives (through their repeated re-telling over time) play a part in producing, embodying and cementing a particular science / astrophysics identity within the habitus. Moreover, they are part of the dialectic through which the workings of capital and field can be 'forgotten' or erased, and the resulting habitus produced as 'natural' (and therefore both legitimate and authentic).

The power of these family narratives (regarding Victor's 'natural' science identity) were further reinforced and legitimated (and hence in turn, cemented further in the habitus) by the wider recognition that Victor also received from others, notably peers and teachers. Although 
we did not interview Victor's teachers and friends, he and his mother both described numerous examples of such recognition of his alignment with STEM identity and a STEM trajectory. For instance, in her Year 13 interview, Sam described how in the end of school student awards, Victor had been voted the 'most likely person to invent something'. As Carlone and Johnson (2007) discuss, it is the combination of both self-recognition and recognition by others that is key to the achievement of a (successful) science identity - or as we would see it, as key to the performance and cultivation of an enduring science habitus.

\section{Masculinity and Victor's physics identity}

So far, we have argued that the combination of habitus, capital and field made Victor's journey to degree level physics less surprising or 'chance' than his opening quote suggests. Now we identify and consider two further aspects which are important parts of the dialectic for understanding Victor and his astrophysics trajectory - masculinity and cleverness.

As noted in the wider literature, physics is a subject/discipline that is strongly aligned with masculinity (e.g. Danielsson 2012, Gonsalves, 2014). Our analysis suggests that it is not the mere fact of possessing a body marked as male that is key, per se, to development of a physics identity and trajectory. Rather, Victor's case suggests that it is his embodiment and enactment of a particular performance of masculinity that is key to the possibilising of his physics identity and trajectory.

Across the eight years that we interviewed Victor, he consistently described his own masculinity (and that of his small group of close friends) as being 'different' to most other boys, although he could not always articulate what this difference was. As he put it in his Year 9 interview, "there's a definite difference between me and say, other ... other boys. And I know there's a difference there but I don't know what it is" (Year 9 interview). Sam concurred:

"He's always been his own boy, he's never sort of followed the ... you know just when he was at junior school you know everyone used to turn up to a disco in a football kit, and he'd go in his cowboy suit kind of thing. [laughs] He doesn't really beat to the drum of other people, he's just always found his own path, and he's never been ... you know if he doesn't want to do something that's it, he's not going not going to do it. But if he's going to do it, he'll do it with all his heart kind of thing". (Sam, Year 13). 
When probed, Victor did identify some particular dimensions of difference. For instance, he explained how, unlike many of their male peers, he and his friends were not 'laddish' (Francis 1999) - for instance, Victor behaved well at school and did not like getting into trouble:

"I know I'm going to be a bit different because, first of all ... well, all my other friends do sort of things that I wouldn't necessarily do, that makes me quite different from them. [...] I sort of act different to them because since I don't like getting in trouble, since I don't like getting in trouble for a laugh, I think that's what makes me different from other students" (Victor, Year 8 interview).

Similarly, Sam described Victor as: "quite a sensitive boy, sort of a bit scared of getting told off and that kind of thing. He does try his best" (Year 6)

More particularly, we read Victor as embodying/performing aspects of what might be termed 'geeky masculinity' - namely being academic, into computer games, being a bit 'square' and 'conservative' rather than into macho masculinity and popular culture and somewhat introverted (see Mendick \& Francis, 2011). He was also aware that some peers positioned him as geeky.

For instance, Victor described feeling distinctive and 'different' from other boys by dint of his high attainment and interest in learning:

"Well, I'd say I'm a bit different. Uh, one of my friends said, in Year 5 [...] everything changed ... and I'm ... I'm in set one, I realised that I was ... I realised that I was the only boy in my ... in our form that was in the top set" (Victor, Year 9) As Francis (2000) discusses, popular laddishness is organised around the performance of 'anti-education' sentiments and derides bookish and studious behaviour as 'unmanly'. Victor himself conveyed some awareness that he might be positioned by some (laddish) peers as 'geeky' in this respect. For example, he recounted an instance when he had been mocked by another boy:

[Name of boy] always ... when I say something, he always says something. He just goes into some really weird voice and then pretends to push up some broken glasses. 
And then he just says 'Oh, I think about stuff' in his really random voice in a sort of weird way (Victor, Year 8).

Victor also eschewed key aspects of laddish popular masculinity, such as a preoccupation with football and drinking. Instead, Victor espoused a slightly more conservative or 'square' masculinity.

He plays guitar in church. He helps out with the young people's club on Friday at church for the little children. [...] He sees his girlfriend $[\ldots]$ um ... and he's going to play Dungeons and Dragons with his friends tonight, that's another thing he likes doing (Sam Year 13)

His performance of masculinity was strongly influenced by his Christian faith, which became more pronounced and important to Victor as he got older.

In contrast to extroverted performances of laddish masculinity, Victor felt different from other boys on account of being, as he termed it, more 'held back' and 'not really outspoken', a trait which he felt he shared with his father:

Different in the fact that I'm a bit more sort of held back, conservative type of thing, not really outspoken. I've probably picked that up from my dad if I'm going to be honest, because he's quite, it's not that he's anti-social. It's just that he gets frustrated at things that aren't going ... like if he knows that something can be better (Victor, Year 11)

As Sam put it:

He's quite quiet on the whole, but has quite strong opinions on things if you ask him. [Victor] is the kind of child who's happiest when he's building Lego, making things. Or his other passion is making comics. Or just ... he's very happy to be left to his own ... to get on with his own thing - he doesn't necessarily need a lot of company (Sam, Year 6).

In his teenage years, Victor and his close friends became avid fans of the computer game Minecraft:

"we have in common the fact that we all like computer games, the thing is, we all are interested in one specific computer game [Minecraft]" (Victor, Year 8). 
His passion for computer games continued as he grew older, as discussed previously, such as his love of space-themed games.

As has been noted in the literature, physics is popularly associated with notions of masculinity. For instance, notions of physics 'natural ability' tend to be strongly dominantly aligned with masculinity (e.g. Carlone 2003). In particular, physics is dominantly aligned with 'geeky' (highly intelligent, socially reserved, non-laddish and video-gaming) performances of masculinity (e.g. see Danielsson, 2012; Gonsalves, 2014; Ong 2005), as epitomised by the character of Sheldon in the US sitcom TV series The Big Bang Theory (see Mendick 2016). We thus read Victor's performances of masculinity as strongly aligning with 'geeky' physics masculinity, and specifically the masculinised notion of the 'physics genius', which supports the possibilising of his science/ astrophysics habitus. Extrapolating from Bourdieu, we suggest that Victor's successful physics trajectory is not only realised through his deployment of capital but also the cultivation of the 'right kind' of masculine habitus and hexis (the expression of habitus through the body), which has incorporated the predominant form of academic, socially reserved, 'geeky' masculinity that is aligned with physics and which, in turn, structures Victor's perception of what is possible and desirable for boys like him. In this respect, we read the interplay between habitus, capital and the fields of physics and masculinity as producing in Victor:

'a socialised body: a structured body, a body which has incorporated the immanent structures of a world or of a particular sector of that world - a field - and which structures the perception of that world as well as action in that world (Bourdieu, 1998, p. 81).

\section{'Cleverness' and Victor's science/ physics identity}

As Bourdieu reminds us, the cultivation of the habitus is a long process. Dispositions are produced through the interplay of different forces and the dialectic between habitus, capital and field:

'continuously defined and redefined in the dialectic between the objectifying intention and the already objectified intention [...], constituted through the confrontation between questions that only exist in and for a mind armed with a particular type of schemes and the solutions obtained through the application of these schemes' (Bourdieu 1990, p. 55). 
Our analysis suggests that Victor's successful consolidation of a physics habitus and trajectory also required him to navigate/ negotiate 'cleverness' - which, as we have written previously, is an inherently classed, gendered and racialized construct that is dominantly aligned with middle-classness, whiteness and masculinity (Archer \& Francis 2007; Archer 2006). As a white, middle-class boy, Victor enjoyed a privileged structural position that made his identification with cleverness easier than for Other students. However, as discussed next, he still experienced difficulties and challenges in maintaining a viable and legitimate alignment with cleverness, and this relationship shifted and changed over time, requiring considerable identity work and deployment of capital in order to maintain Victor's possibility as 'clever'.

As we have written previously, science in general, but physics in particular, is strongly aligned with notions of cleverness (Archer et al., under review; 2013, 2012). Indeed, our research shows that physics is widely recognised by students as being the 'most difficult' science. In England, school physics also exercises forms of gatekeeping (such as grading examinations more severely and setting higher entry criteria in comparison to other subjects) which both reinforce and produce the alignment with cleverness. Hence, we argue that for Victor to develop a physics habitus and trajectory, he had to negotiate a viable relationship with 'cleverness'.

At each interview from Year 6 to Year 11, we asked Victor the same question ("Do you think you have to be clever to be into science?") As can be seen below, his responses changed over time:

Y6: "You don't have to be clever to do science"

Y8: "I think you have to be a little clever because you have to know about Science in the first place, you have to want to study the subject, yeah, you probably have to be quite clever in the subject to want to learn about it"

Y9: “People keen on Science ... um they're sort of ... they're not average people, they're more ... they're more clever, they're cleverer than most people"

Y11: “Er, yeah, you need it, yes. Mainly because sort of you can’t just enter Science without knowing what's really happening I think. If you're going to go into Science 
you need to know what's going on and to know what's going on you need to learn and sort of and then in order to learn you need to sort of either sort of revise or just technically, naturally be clever, sort of".

We interpret the above examples as showing a pattern in which, from an early more egalitarian view (in which "you don't have to be clever to do science"), Victor increasingly aligns science notions of cleverness (whereby one needs to be "naturally clever"). As such, we might view the above pattern of changing responses as hinting at the cultivation of his habitus, through interaction with the field of physics. The importance of cultivating such dispositions is, according to Bourdieu, related to the reproduction of elite institutions, of which, we would argue, physics is a prime example:

\footnotetext{
"An institution [...] is complete and fully viable only if it is durably objectified not only in things, that is, in the logic transcending individual agents, of a particular field, but also in bodies, in durable dispositions to recognize and comply with the demands immanent in the field' (Bourdieu, 1990, p.58).
}

Victor's changing views are not uncommon and similar patterns were found among many of his peers in the wider data set. We interpret these shifts as reflecting pedagogic action by the field, in which physics is strongly aligned with notions of cleverness, as part of the reproduction of the subject's elite status. While the link between science and 'cleverness' reflects a wider dominant societal stereotype of science - which we see as playing an important role in the reproduction of science's elite status - as his Year 9 interview highlights, it also required Victor (in his development of a science/ physics habitus) to personally negotiate a relationship with 'cleverness' in order to be recognised (and to self-recognise) as a legitimate potential scientist.

Early on in his interviews, despite his view that "you don't have to be clever to do science", Victor identifies himself and is identified by others (notably his mother) as being 'clever'. As Sam put it in the Year 6 interview, "I think he's a very clever kid". However, as Victor starts to develop the disposition that a person needs to be clever to do physics, he also experiences challenges to his own identification as such, which require navigation. These negotiations 
were exemplified his Year 9 interview, when Victor struggled to reconcile his science habitus with his location in the second set for science:

"Enjoying it [science] has gone down a bit because like there's ... I've always been in second set Science, I don't know why I haven't been in top set but it's like I was thinking oh yeah, I got a 7 in ... 7A, 8C ... I think I got an 8C in one of the Sciences and I was like 'Oh yeah, that should get me up to the top set' and then I didn't ... I don't know why I didn't go up to the next set. And so I was ... I didn't know what was going on for a long time and then apparently my mum had spoken to ... I think it was [name of science teacher] ... but he said the second set should be the top set but then there's special people in the year that can really excel. But I was just thinking but I'm really doing well in Science as well so I sort of got the feeling that people in the top set were super-geniuses and the people in the second set were just clever".

As the above extract suggests, Victor felt profoundly confused around this time with his location in the second set for science - which sat at odds with his sense of self (as a 'clever' student) and other alleged markers of his cleverness (such as his attainment). Sam also became involved in these negotiations (going into school to speak to the science teacher) and, in the end, Victor negotiated an understanding that enabled him to align himself with cleverness by positioning the top set as exceptions ('super-geniuses').

In his Year 11 interview, Victor reproduced a dominant physics discourse of the 'effortless/ naturally clever physicist', that we found to be common among A level physics students across the wider sample ("If you're going to go into Science ... you need to sort of either sort of revise or just technically, naturally, be clever"). As noted earlier, Sam's strong discourse of 'natural' science talent fits well with his alignment with 'natural cleverness':

"I don't know sort of how natural cleverness comes round ... but I've always been told that I'm naturally clever in sort of logical understanding of things. But I do think that you need to be, have some base knowledge or pretty much base knowledge of Science itself, but then for the particular aspects of Science you need specialist qualities" (Year 11).

In Year 13, Victor had to negotiate another major challenge concerning 'cleverness' which threatened his continued physics trajectory, when his school did not predict him to attain the 
top (A/ A* grade) A level results. At this point, Sam played a key role in developing and enacting a strategy to navigate the challenge, which involved systematically sifting through every HEIs physics degree entry requirements (alongside exploring non-degree astrophysics apprenticeship routes). As Sam explained:

"So we've looked at universities that do Astrophysics, we've tried to eliminate any universities that want $A * s \ldots$ we wrote down every single university that did Astrophysics. We ruled out anything that wanted A*s and As" (Sam, Year 13)

This strategy paid off and Victor gained access to a university astrophysics degree. Alongside the practical work that Sam put in to securing his continued trajectory, Victor also engaged in focused identity work, to possibilise himself (as a non-A grade student) as a potential physics degree student. For instance, he recounted a discussion that he had held with a physics lecturer whom he had met on a university open day, where lower grades were re-framed in a more positive light:

I was speaking to one of the people, one of the heads in the Physics department and they were talking about how all the $\mathrm{A}^{*}, \mathrm{~A}$, A people, quite a lot of them tend to drop out instead of the people that got B, B, C. [...] I found that quite interesting (Victor, Year 13).

Bourdieu described habitus as the 'art of inventing'. We suggest that Victor's data hint at how this art of invention plays out in practice, through strategic manoeuvres (to support and facilitate the required attainment and access to physics courses and routes) and through the identity work - but specifically, the negotiations of a 'clever' identity - that are required to remain a possible/ viable scientist/ physicist.

\section{Discussion and Conclusions}

"Nothing is more misleading than the illusion created by hindsight in which all the traces of a life $[\ldots]$ appear as the realization of an essence that seems to pre-exist them' (Bourdieu, 1990, p.55)

In this chapter we have argued that Victor's physics identity and trajectory is the not the sole result of 'chance' or 'mistake' - nor is it the inevitable product of an essentialised or innate 
talent or aptitude. Rather, our Bourdieusian inspired analysis suggests that Victor's trajectory was the product of lots of hard (conscious and unconscious) work by him and his family, which included the strategic deployment of capital and revealed how the field of physics demands, and achieves, the cultivation of a particular 'clever', 'geeky' masculine habitus/hexis.

Our application of this analytic lens suggests that it was, in many ways, unsurprising that Victor went on to pursue a STEM degree, given the volume and nature of his science-related family habitus and capital. We interpret the data as revealing a consistent trajectory over the years, involving the cultivation of a distinctive physics habitus - but this process requires concerted work, resourcing, strategizing and navigation by Victor and his family. The mere possession of capital was insufficient on its own. Victor's trajectory also required realisation through the negotiation, cultivation and external recognition of a specific masculine, 'clever' habitus.

To return to Victor's analogy with which we opened the chapter, Victor's astrophysics identity and trajectory required many 'fuses' and repeated 'sparks'. We interpret the ongoing interaction of fuses and sparks as produced through interactions of habitus and capital with the fields of science, physics and the subfield of school physics.

As Victor himself suggested at the age of ten, in many ways, Victor had always 'known' that he would study science at university - although his trajectory was not always certain and required considerable effort, work and deployment of capital in order to realise this ambition. Moreover, we suggest that his eventual success (being accepted on to an astrophysics degree course) was strongly facilitated by the web of multiple fuses and sparks which surrounded him. We hypothesise that his successful trajectory would have been much more uncertain had he only had a single fuse and/or spark. His success is also underscored by the cultivation of a habitus that is normalised and demanded by physics. That is, his 'different', academic, 'geeky' masculinity and his achieved alignment with cleverness (though the latter was often threatened and required negotiation), was cultivated through his identification with, investment in, and desire for the field (what Bourdieu would term, illusio). Victor's viable physics habitus was affirmed/valued and reinforced through his encounters with physics, and, in turn, we argue, now plays a part in the ongoing constitution and reproduction of the elite nature of the field. In other words, Victor's trajectory was both enabled and possibilised by specific configurations of habitus and capital and by his conformity to the dominant notion of 
the masculine, 'clever', 'geeky' physicist. Now, as a physicist himself, Victor's embodiment of the demands of the field contributes, in turn, to the ongoing reproduction of the 'reality' and legitimacy of this association.

While Bourdieu argues that economic capital is 'at the root of all the other types of capital' (Bourdieu, 1986, p. 24), from our analysis we suggest that Bourdieu's prioritisation of social class obscures the simultaneous importance of gender and 'race' in the social reproduction of physics. While we have not had the space to consider race/ethnicity here, we suggest that our analyses point to an underlying pedagogic action which is aimed at the reproduction of gender privilege (specifically masculinity) in and through the reproduction of physics.

We suggest that the application and integration of a feminist Bourdieusian lens provides additional insights to those provided by a Butlerian lens alone. First, it highlights the importance of capital for enabling, possibilising and realising performances of physics identity and a viable physics trajectory. Second, Bourdieu's concept of field (in interaction with habitus and capital) reveals how particular practices are key for determining the scope and viability of performances of physics identity, particularly, highlighting the slow but inexorable, long-standing cultivation of a physics habitus - which extends powerfully beyond momentary identity performances. In other words, we suggest that the combination of lenses helps us to keep hold of both structured agentic nature of Victor's gendered physics identity and trajectory.

To conclude, we suggest that Victor's case helps us to understand why existing patterns of participation in post-compulsory physics remain low, patterned and resistant to change. That is, inequalities in physics participation are not simply due to differential levels of interest in physics. Rather, they can be understood as produced by the field of physics itself, which requires particular (and demanding) configurations and negotiations of habitus, capital and masculinity in order to maintain a physics trajectory. It could be said that there are only so many Victors in the world who can embody and possess these requirements. We interpret our analyses as also suggesting that if we are to disrupt and change these patterns, then the key will be to change the field - notably the dominant norms, values and habitus that it demands for its elite reproduction. This will mean disrupting dominant associations of physics with masculinity and cleverness. Such an endeavour is, of course, far from simple, and would need to extend across multiple fields, from the popular media (and representations of physics and physicists) through to educational practices (e.g. addressing the current grade severity in 
Advanced level physics in England) and the culture of school and post-compulsory and professional physics. With regard to the latter, we suggest that one small, but potentially significant, marker of change might be that teachers and students describe and view physics as no 'harder' than any other subject.

\section{References}

Adkins, L. (2004). Introduction: Feminism, Bourdieu and after. The Sociological Review, 52, 1-18. doi:10.1111/j.1467-954X.2005.00521.x

Archer, L., DeWitt, J., Osborne, J., Dillon, J., Willis, B. and Wong. B. (2012). "Balancing acts": Elementary school girls' negotiations of femininity, achievement, and science. Science Education, 96 (6), 967-989. doi: 10.1002/sce.21031.

Archer. L., DeWitt, J., Osborne, J., Dillon, J., Willis, B. \& Wong, B. (2013). №t Girly, not sexy, not glamorous: Primary school girls' and parents' constructions of science aspirations. Pedagogy, Culture \& Society, 21 (1), 171-194. doi: 10.1080/14681366.2012.748676.

Archer, L., DeWitt, J., Osborne, J., Dillon, J., Willis, B. \& Wong, B. (2012). Science Aspirations, Capital and Family Habitus: How families shape children's engagement and identification with science. American Educational Research Journal, 49(5), 881-908. doi:10.3102/0002831211433290.

Archer, L., Moote, J., Francis, B., DeWitt, J., \& Yeomans, L. (2017). The "Exceptional" Physics Girl: A Sociological Analysis of Multimethod Data From Young Women Aged 10 16 to Explore Gendered Patterns of Post-16 Participation. American Educational Research Journal, 1-39. doi:10.3102/0002831216678379.

Archer, L., Moote, J., \& MacLeod, E. (under review). "You can’t handle the truth!" Pedagogic work and the cultivation of student habitus in the reproduction of Advanced Level Physics as an elite subject. American Educational Research Journal.

Bourdieu, P. (1986). "The Forms of Capital." In Handbook of Theory and Research for the Sociology of Education, edited by J. G. Richardson, 241-258. New York: Greenwood Press. Bourdieu, P. (1990). The Logic of Practice. Cambridge, UK: Polity Press. 
Bourdieu, P. (1993). The field of cultural production: Essays on art and literature.

Cambridge: Polity Press.

Bourdieu, P. (1998). Practical Reason. Cambridge: Polity Press.

Bourdieu, P. (2001). Masculine Domination, R Nice (Trans). Cambridge: Polity Press.

Originally published as La Domination Masculine (Paris: Seuil)

Bourdieu, P. (2010). Sociology is a martial art. New York, NY: New Press.

Bourdieu, P., \& Wacquant L. J. D. (1992). An Invitation to Reflexive Sociology. Cambridge: Polity Press.

Carlone, H. B. (2003). (Re)producing good science students: Girls' participation in high school physics. Journal of Women and Minorities in Science and Engineering, 9, 17-34. DOI: 10.1615/JWomenMinorScienEng.v9.i1.20.

Carlone, H. B., \& Johnson, A. (2007). Understanding the science experiences of successful women of color: Science identity as an analytic lens. Journal of Research in Science Teaching, 44(8), 1187-1218. doi:10.1002/tea.20237.

Danielsson, A. T. (2012). Exploring woman university physics students "doing gender" and "doing physics." Gender and Education, 24(1), 25-39. DOI: 10.1080/09540253.2011.565040.

DeWitt, J., Archer, L., \& Mau, A. (2016). Dimensions of science capital: exploring its potential for understanding students' science participation, International Journal of Science Education, 38(16), 2431-2449. doi:10.1080/09500693.2016.1248520.

Dika, S. L., \& Singh, K. (2002). Applications of social capital in educational literature: A critical synthesis. Review of Educational Research, 72(1), 31-60. doi:10.3102/00346543072001031.

Francis, B. (1999). Lads, Lasses and (New) Labour: 14-16-year-old students' responses to the 'laddish behaviour and boys' underachievement' debate. British Journal of Sociology of Education, 20(3), 355-371. doi:10.1080/01425699995317.

Francis, B. (2000). The gendered subject: Students' subject preferences and discussions of gender and subject ability. Oxford Review of Education, 26, 35-48.

doi:10.1080/030549800103845. 
Gonsalves, A. (2014). "Physics and the girly girl—-there is a contradiction somewhere": Doctoral students' positioning around discourses of gender and competence in physics. Cultural Studies in Science Education, 9, 503-521. DOI: 10.1007/s11422-012-9447-6.

Israel, G. D, Beaulieu, L. J., \& Hartless, G. (2001). The influence of family and community social capital on educational achievement. Rural Sociology, 66, 43-68. doi:10.1111/j.15490831.2001.tb00054.x

Lareau, A. (2003). Unequal childhoods: Class, race and family life. Berkeley: University of California Press.

Lemke, J. L. (1990). Talking science: Language, learning, and values. Westport, CT: Ablex. Martin, N. D. (2009). Social capital, academic achievement, and postgraduation plans at an elite, private university. Sociological Perspectives 52, 185-210.

doi:10.1525/sop.2009.52.2.185.McCall, L. (1992): Does Gender Fit? Bourdieu, Feminism, and Conceptions of Social Order. Theory and Society, Vol. 21, No. 6, 837-867

McLeod, J. (2005). Feminists re-reading Bourdieu: old debates and new questions about gender habitus and gender change. Theory and research in education, 3(1), 11-30. doi:10.1177/1477878505049832.

McNay, L. (1999). Gender, Habitus and the Field: Pierre Bourdieu and the Limits of Reflexivity. Theory, Culture \& Society 16(1): 95-117. doi:10.1177/026327699016001007. Mendick, H. (2016). Gender and physics: a sociological approach. Physics Education, 51(5), 1-6. DOI: 10.1088/0031-9120/51/5/055014 Ong, M. (2005). Body projects of young women of color in physics: Intersections of gender, race, and science. Social Problems, 52, 593617. DOI: $10.1525 / \mathrm{sp} .2005 .52 .4 .593$

Osborne, J., \& Dillon, J. (2008). Science Education in Europe: Critical Reflections. A report to the Nuffield Foundation. King's College London, London.

Perna, L. W., \& Titus, M. A. (2005). The Relationship between Parental Involvement as Social Capital and College Enrollment: An Examination of Racial/Ethnic Group Differences. The Journal of Higher Education, 76(5), 485-518. doi:10.1080/00221546.2005.11772296 Sandefur, G.D., Meier, A., \& Campbell, M. (2006). Family resources, social capital and college attendance. Social Science Research, 35, 525-553.

Vincent, C., \& Ball, S. (2007). Childcare, choice and class practices. London: Routledge. 
Webb, J., Schirato, T. and Danaher, G. (2002). Understanding Bourdieu. Sydney: Allen \& Unwin

' One girl, Hannah, had also entered a physics degree course, a number of students had entered STEM degree or engineering courses and a small number of other students were in the process of taking a 'gap year', some of which included re-applying for physics degree courses.

ii Scientists as odd: $\mathrm{x}^{2}(4,2227)=82.655, \mathrm{p}<.001$, Cramer's V=.193, indicating a very large effect; Scientists as geeky: $\mathrm{x}^{2}(4,2227)=38.279, \mathrm{p}<.001$, Cramer's $\mathrm{V}=.131$, indicating a large effect size; Scientists as male: $\mathrm{x}^{2}(4,2228)=101.154, \mathrm{p}<.001$, Cramer's $\mathrm{V}=.213$, indicating a very large effect). 